University of Nebraska - Lincoln

DigitalCommons@University of Nebraska - Lincoln

Faculty Publications, Department of Child, Youth, and Family Studies

Child, Youth, and Family Studies, Department of

2020

\title{
Emotional Support and Mental Health Among Somali Men in a Rural Midwestern Town
}

Julie A. Tippens

University of Nebraska-Lincoln, jtippens@unl.edu

Gilbert R. Parra

University of Nebraska-Lincoln, gparra2@unl.edu

Patrick Habecker

University of Nebraska-Lincoln, phabecker2@unl.edu

Kimberly Gocchi Carrasco

University of Nebraska-Lincoln, kstarlin2@unl.edu

Arthur R. Andrews III

University of Nebraska-Lincoln, arthur.andrews@unl.edu

See next page for additional authors

Follow this and additional works at: https://digitalcommons.unl.edu/famconfacpub

Part of the Developmental Psychology Commons, Family, Life Course, and Society Commons, Other

Psychology Commons, and the Other Sociology Commons

Tippens, Julie A.; Parra, Gilbert R.; Habecker, Patrick; Carrasco, Kimberly Gocchi; Andrews, Arthur R. III; Palmer-Wackerly, Angela L.; Chaidez, Virginia; Soliz, Jordan; PytlikZillig, Lisa M.; and Dombrowski, Kirk, "Emotional Support and Mental Health Among Somali Men in a Rural Midwestern Town" (2020). Faculty Publications, Department of Child, Youth, and Family Studies. 289.

https://digitalcommons.unl.edu/famconfacpub/289

This Article is brought to you for free and open access by the Child, Youth, and Family Studies, Department of at DigitalCommons@University of Nebraska - Lincoln. It has been accepted for inclusion in Faculty Publications, Department of Child, Youth, and Family Studies by an authorized administrator of DigitalCommons@University of Nebraska - Lincoln. 


\section{Authors}

Julie A. Tippens, Gilbert R. Parra, Patrick Habecker, Kimberly Gocchi Carrasco, Arthur R. Andrews III, Angela L. Palmer-Wackerly, Virginia Chaidez, Jordan Soliz, Lisa M. PytlikZillig, and Kirk Dombrowski 


\title{
Emotional Support and Mental Health Among Somali Men in a Rural Midwestern Town
}

\author{
Julie A. Tippens, ${ }^{1}$ Gilbert R. Parra, ${ }^{1}$ Patrick Habecker, ${ }^{2}$ \\ Kimberly Gocchi Carrasco, ${ }^{2}$ Arthur R. Andrews III, ${ }^{3}$ \\ Angela L. Palmer-Wackerly, ${ }^{4}$ Virginia Chaidez, ${ }^{5}$ \\ Jordan Soliz, ${ }^{4}$ Lisa M. Pytlik Zillig, ${ }^{6}$ \\ and Kirk Dombrowski ${ }^{2}$
}

\footnotetext{
1 Department of Child, Youth and Family Studies, University of Nebraska-Lincoln

2 Department of Sociology, University of Nebraska-Lincoln

3 Department of Psychology and Institute for Ethnic Studies, University of Nebraska-Lincoln

4 Communication Studies, University of Nebraska-Lincoln 5 Nutrition and Health Sciences, University of Nebraska-Lincoln

6 Public Policy Center, University of Nebraska-Lincoln

Corresponding author - Julie A. Tippens, Department of Child, Youth and Family Studies, University of Nebraska-Lincoln, 205 Louise Pound Hall, Lincoln, NE 68588 Email: jtippens@unl.edu
}

\begin{abstract}
Perceived social support has been correlated with refugees' positive mental health outcomes; yet, little is known about the perceived sources of support after secondary migration to new-destination rural towns. Somali refugee men $\left(n_{-} 49\right)$ residing in a rural Midwest United States community were recruited using respondent-driven sampling to complete a self-administered structured survey in English or Somali using audio computer-assisted self-interview software. Questions assessed perceived
\end{abstract}

Published in Journal of Rural Mental Health 44:3 (July 2020), pp 170-183.

doi:10.1037/rmhoooo136

Copyright (c) 2020 American Psychological Association. Used by permission.

Submitted May 21, 2019; revised March 5, 2020; accepted March 12, 2020 
sources of support, psychological distress, and happiness. Somali participants reported low utilization of both informal (30.4\%) and formal (24.4\%) supports when sad, stressed, or worried. Two thirds of participants reported low levels of distress and $98 \%$ reported being happy or very happy. This exploratory research contributes to understandings of Somali men's perceived support in a postsecondary migration setting. We discuss implications for social support interventions and culturally tailored assessment, diagnoses, and treatment to enhance Somalis' support and psychological well-being.

Keywords: refugees, social support, determinants of health, help seeking, United States

The United States is a major destination country for Somali refugees (Huisman, 2011; Kapteijns \& Arman, 2008). Third-country resettlement, the permanent relocation of refugees from an asylum country to a new country, is considered the last durable solution by the international humanitarian community and is reserved for cases in which voluntary repatriation and local integration are not possible (United Nations Refugee Agency, 2019). Refugees selected for the United States resettlement program do not have a choice in where they will live (Mott, 2010); resettlement has typically occurred in urban areas in which local refugee resettlement agencies arrange short-term housing as well as monetary, employment, and medical assistance (Marks, 2014; United States Department of Health and Human Services, Administration for Children and Families, Office of Refugee Resettlement, 2015). Although refugees traditionally arrived in large United States cities, there has been a greater focus in the past three decades to resettle refugees in smaller cities and suburban towns (Bose, 2018). New formal resettlement patterns have been coupled with secondary migration of refugees to rural destinations. Little is known about the health, well-being, and perceived social support of refugees residing in rural United States towns, despite the fact this is an increasing phenomenon (Gilhooly \& Lee, 2017).

Perceived social support refers to the cognitive appraisal of connection to other individuals (Streeter \& Franklin, 1992) and has been associated with improved mental health status (Kawachi \& Berkman, 2001; Lakey \& Orehek, 2011). Perceived support has been conceptually linked to mental health in two primary ways: (a) by buffering or moderating against the adverse effects of stress, and (b) by providing individuals a sense of meaningful social roles in tandem with access to health-promoting forms of support (Almeida, Molnar, Kawachi, 
\& Subramanian, 2009; Cohen \& Wills, 1985; Lakey \& Orehek, 2011). Social support has been conceptualized as multidimensional with at least four functions of support (i.e., instrumental, emotional, informational, and companionship; Cohen \& Wills, 1985), although effects of support on mental health often emphasize emotional support (e.g., Tonsing, Zimet, \& Tse, 2012). Emotional support is frequently divided into familial and friend support, though multiple other relationship types may provide support in both informal (e.g., elder or religious leader) and formal (e.g., mental health professional) roles. For refugees and immigrants, postmigration settlement is a major life event (Puyat, 2013) and is often characterized by disruption of social support through contraction of social networks, loss of social roles, language barriers, discrimination, limited economic assets, and reduced access to culturally meaningful resources (Goodkind, 2006; Goodkind et al., 2014; Puyat, 2013).

Social networks in new receiving communities play a key role in refugees' well-being (Stewart et al., 2008). Family separation and disrupted family dynamics have been associated with refugees' psychological distress (Schweitzer, Greenslade, \& Kagee, 2007), whereas perceived support from family and ethnic community has generally been associated with better psychosocial and mental health (Abraham, Lien, \& Hanssen, 2018; Beiser, 1999; Marmot et al., 1975; Schweitzer, Melville, Steel, \& Lacherez, 2006; Silveira \& Allebeck, 2001; Simich, Beiser, \& Mawani, 2003; Tippens, 2020). There is mixed evidence pertaining to whether support from members of the new country's host community enhances African refugees' subjective well-being and mental health. Schweitzer et al. (2007) found that support from one's wider community did not affect emotional and mental health while Muhwezi and Sam (2004) identified support from the host community as a buffer against postmigration stressors. We attempt to contribute to the gap in knowledge pertaining to refugees' health and wellbeing in secondary migration contexts by examining relationships between Somali men's perceived support and mental health.

\section{Background}

Somali im/migration to the United States has been described as occurring in two distinct waves (Kapteijns \& Arman, 2008). Just 9 years 
after Somalia's independence, the Supreme Revolutionary Council, led by Mohamed Siad Barre, deposed the president and prime minister in 1969 (Adam, 1992). After this 1969 military coup, many Somalis migrated to the United States for work or study; as Siad Barre's dictatorial rule spread in the 1980s, the Somali diaspora expanded across the country, comprised primarily of students, asylum seekers, and refugees with the economic capability to move abroad (Kapteijns \& Arman, 2008). The second wave of Somali immigration occurred following the collapse of the Siad Barre regime in 1991 (Kapteijns \& Arman, 2008; Walls, 2009). Despite multiple peace negotiations and attempts to install a national government, sectarian violence left Somalia without a permanent central government between 1991 and 2012 (Abdi, 2007; BBC, 2018; Human Rights Watch, 2011). In the years following Siad Barre's ejection from power, Somalia became characterized by both an increase in militarism and the advent of warlordism (Adam, 1992); more than 300,000 civilians died as a result of violence and famine during this time and another two million persons were displaced (Hammond, 2014; Internal Displacement Monitoring Centre, 2006).

Somalis were designated a priority group for United States resettlement in the early 2000 s and represented the majority of African refugee arrivals for a number of years (Huisman, 2011). In fact, between 2000 and 2018 nearly 104,000 Somalis were resettled in the United States (Refugee Processing Center, n.d.). This second wave of Somalis had spent a significant time displaced in camps and cities in Ethiopia, Kenya, and Yemen between fleeing Somalia and being resettled in the United States (Kapteijns \& Arman, 2008). Somalis from this group have been resettled in 45 states across the United States, largely concentrated in metropolitan areas but with high rates of secondary migration, including to new destination rural towns in the Midwest (Centers for Disease Control and Prevention, 2018; Huisman, 2011; Kapteijns \& Arman, 2008).

Few studies have been conducted on the mental health of African immigrant and refugee groups (Pavlish, Noor, \& Brandt, 2010), and research with Somalis has primarily focused on trauma and posttraumatic stress disorder (PTSD; Lincoln, Lazarevic, White, \& Ellis, 2016). Predisplacement factors that affect Somalis' mental health include exposure to civil war and sectarian violence, torture, famine, and family loss and separation (Abdi, 2007; Carroll, 2004; Jaranson et al., 2004; Shannon, Wieling, McCleary, \& Becher, 2015). Somalis have reported 
higher trauma exposure compared to other refugee groups, which has been associated with physical and psychological symptoms, including PTSD, depression, and anxiety (Bentley, Thoburn, Stewart, \& Boynton, 2012; Bhui et al., 2003; Gerritsen et al., 2006; Halcón et al., 2004; Jaranson et al., 2004; Matheson, Jorden, \& Anisman, 2008). Transit factors associated with poor mental health include protracted stays in refugee camps, sexual violence, and lack of basic necessities, such as food and housing (Abdi, 2007; Perera et al., 2013). Finally, postmigration stressors reported by Somali refugees living in the United States include housing problems, employment difficulties, and adjustment difficulties (Perera et al., 2013). Kleist (2010) found that Somali refugees resettled in Denmark described men's postmigration difficulties as being worse due to the transfer of male authority to 'the welfare state.' (Abdi, 2014, p. 46o) conceptualizes this as an extension of a "male breadwinner-female homemaker binary" that accompanied increased religiosity in Somalia since the conflict and clashed with Somali refugees' reality of reliance on public assistance in the United States. Indeed, shifting gender roles have been identified as undermining Somali men's self-perceptions of masculinity and diminishing their self-esteem and dignity in postmigration settings (Warfa et al., 2012).

In addition to Somalis' shifting postmigration social and familial roles, Ellis et al. (2010) stated that Somali immigrants and refugees residing in the United States are in, at minimum, "triple jeopardy" of discrimination due to being refugees, racialized as Black, and predominantly Muslim. Experiences of xenophobia, racism, and Islamophobia seem to place Somalis at increased risk for poor mental health outcomes.

\section{Context of the Present Study}

The presented exploratory, hypothesis-generating study is part of an ongoing effort by the Minority Health Disparities Initiative (MHDI) at the University of Nebraska to address the health of rural communities residing in the state. The specific town has a population of approximately 10,000 and is classified as a nonmetro, micropolitan area by the United States Department of Agriculture (2019). The opening of a meatpacking plant in 1990 attracted immigrants and refugees; the town has experienced a demographic inversion such that 
immigrant residents now comprise the majority of residents. In addition to an increase in the numbers of Latinx immigrants over the past two decades, high rates of secondary migration exist among Somali refugees who were initially resettled in different locations and moved for employment in the meatpacking industry. The meatpacking industry depends heavily on an immigrant labor force, which frequently drives migration. Traditionally, Latinx workers occupied these positions (Broadway, 2007) yet increasing numbers of refugees from Africa, including Somalis, have diversified the labor force in recent years across the United States (Huisman, 2011; Mott, 2010; Shandy \& Fennelly, 2006). The exact number of Somalis living in the presented town is unknown but has been estimated to be approximately 1,500 . Since the town is not a federally designated refugee resettlement location, there are no resettlement agencies to support newcomers; however, a Somali community center provides assistance to refugees who have moved to the town. Although there have not been any reports of hate crimes against members of the town's Somali population, the city council denied the Islamic Center's application to expand its location fewer than 5 years ago. The American Civil Liberties Union intervened, warning of religious discrimination, and a permit was eventually granted by the council.

The MHDI as been engaged in community-based participatory research with community leaders, health professionals, and service providers in the town. Community partners approached the MHDI to conduct a health needs and assets survey, as accurate data did not previously exist given the demographic shift. This study provides descriptive statistics on social support and mental health as well as an examination of the relationship between social support and mental health among Somali refugee men residing in a rural Midwestern town.

\section{Method}

\section{Participants and Procedures}

Participants were recruited using respondent-driven sampling (RDS), a type of chain-referral recruitment that relies on respondents to recruit subsequent participants within their social networks using a limited number of "coupons" that, when exchanged, provide the 
referring participants with additional compensation (Gile \& Handcock, 2010; Heckathorn, 2002). RDS has been used with hard-toreach immigrant and refugee populations in health research (Keygnaert et al., 2014; Montealegre, Risser, Selwyn, McCurdy, \& Sabin, 2013; Rhodes et al., 2012). Each individual who completed an interview was provided with up to three coupons, which they could give to others who were eligible for this study. Participants were given $\$ 20$ for completing the survey and an additional $\$ 10$ for each coupon that resulted in a completed interview. Recruitment was restricted to those who were 19 or older (the age of majority in the state where data were collected) and who lived in the town. Participants completed a self-administered survey in English or Somali using audio computer-assisted self-interview. For this study, only participants who identified as Somali and who were born outside of the United States were included. The sample included 53 Somali refugees. The majority of Somali refugees were men $(92.5 \%)$. Because there were only three Somali women and one participant who did not answer the gender question, we elected to focus analyses on Somali men ( $n$ = 49; Mage $=41.21 ; S D=14.84)$. This study was approved by the Human Research Protection Program at the University of Nebraska-Lincoln. All procedures were performed in accordance with the ethical standards of the 1964 Helsinki Declaration and its later amendments. Informed consent was obtained from all individual participants included in the study.

\section{Measures}

Sociodemographic characteristics. Participants were asked their age, sex, household income ( $1=\$ 0$ to $\$ 1,200,2=\$ 1,201$ to $\$ 1,750$, $3=\$ 1,751$ to $\$ 2,150,4=\$ 2,151$ to $\$ 3,100,5=\$ 3,101$ to $\$ 4,500,6=$ $\$ 4,501$ to $\$ 5,500$, and $7=\$ 5,501$ or more), number of years residing in the current location ( $1=10$ years or longer, $2=6-9$ years, $3=3-5$ years, $4=1-2$ years, and $5=$ less than one year; this variable was recoded so that higher scores represent more years in the current location), and average months spent in current location annually ( $1=$ 12 months/the entire year, 2 = about 9 months/most of the year, $3=$ about 6 months/about half of the year, and $4=$ About 3 months/not much of the year; this variable was recoded so that higher scores represent more months per year spent in current location). 
Sources of perceived emotional support. Participants were asked, "The last time you were feeling sad, stressed or worried, did you turn to any of the following people for support or advice?": elder family/ clan member, family/clan member about your own age, friend, doctor, healer (defined here as health worker outside of the formal health or biomedical systems, e.g., spiritual healer), community health worker, mental health professional, religious leader, community leader. Participants were asked to answer yes (coded 1) or no (coded o) for each person. A measure of informal support was created by considering the following individuals: elder family/clan member, family/clan member about your own age, and friend. Specifically, a binary index of informal support was created by categorizing those individuals who reported at least one informal supportive person the last time they felt sad, stressed or worried as yes and those who reported no informal supportive people the last time they felt sad, stressed or worried as no. A measure of formal support was created by considering the following individuals: doctor, healer, community health worker, mental health professional, religious leader, and community leader. Specifically, a binary index of formal support was created by categorizing those individuals who reported at least one formal supportive person the last time they felt sad, stressed, or worried as yes and those who reported no formal supportive people the last time they felt sad, stressed, or worried as no.

Distress. Distress was measured using the six-item Kessler Psychological Distress Scale (K6), a six-item measure of distress (Kessler et al., 2003). The K6 was designed to assess global distress with an emphasis on symptoms of depression and anxiety and has been used in multiple large national and international studies as a screening measure for internalizing mental health difficulties (e.g., the National Health Interview Survey or World Health Organization Mental Health Surveys). The measure has been translated into 21 languages. The Somali version used in this study was translated by a female Somali community health worker (CHW) and checked by a second female Somali $\mathrm{CHW}$; both collected data from Somali participants.

Participants rated how frequently they experienced each symptom during the previous 30 days ranging from 1 (All of the time) to 5 (None of the time). Each item was recoded so that o represented None of the time and 4 represented All of the time. Example items were "During the past 30 days, how often did you feel worthless?" and "During the 
past 30 days, how often did you feel nervous?" The K6 is scored by summing scores from each item with higher scores represent higher levels of distress. Internal consistency in this sample was high $(\alpha=$ .74). Findings from prior work indicate the scores of 13 or above discriminate cases of serious mental illness from noncases (Kessler et al., 2003). Research also suggests that scores between 5 and 12 reflect moderate levels of psychological distress (Prochaska, Sung, Max, Shi, \& Ong, 2012).

Happiness. Happiness was measured with one item: "How would you rate your happiness?" Participants were asked to rate the item on a 5-point Likert scale ranging from 1 (Very happy) to 5 (Not at all happy). This item was reversed coded such that higher values represented higher levels of happiness. There is some evidence that suggests a single item measure of happiness is related in expected directions to several established measures of emotional well-being, which supports its validity (Abdel-Khalek, 2006; Moldovan, 2017; Rego, Machado, Leal, \& Cunha, 2009). Previous research supports the use of self-reported happiness with Somali refugees (e.g., Pratt et al., 2017). Additionally, there is evidence from qualitative research with Somalis that being together with families/friends brings happiness (McMichael \& Ahmed, 2003) and that "loss of happiness" and "inability to feel happiness" are major causes of distress among Somali refugees (Schuchman \& McDonald, 2008).

\section{Results}

Descriptive statistics for study variables are presented in Table 1. As shown, the average age was 41.21 years $(S D=14.84)$. The majority of individuals reported a monthly income between $\$ 1,201$ and $\$ 1,750$. A large percentage of individuals (42.9\%) reported living in their current location for 10 years or longer; nearly one in five participants (18.4\%) reported living in their current location for less than 1 year. Most individuals (65.3\%) reported residing in their current location for the entire year. With regard to perceived support, the percentages that reflect whether individuals turned to different supportive others the last time they felt sad, stressed, or worried ranged from $11.1 \%$ (mental health professional) to $28.3 \%$ (family/clan member about your age). Consistent 
Table 1. Descriptive Statistics for Study Variables

\begin{tabular}{|c|c|c|}
\hline Study variables & $M$ or $\%$ & $S D$ \\
\hline \multicolumn{3}{|l|}{ Sociodemographic characteristics } \\
\hline Age & 41.21 & 14.84 \\
\hline \multicolumn{3}{|l|}{ Monthly income } \\
\hline$\$ 0$ to $\$ 1,200$ & $22.4 \%$ & \\
\hline$\$ 1,201$ to $\$ 1,750$ & $69 \cdot 4 \%$ & \\
\hline$\$ 1,751$ to $\$ 2,150$ & $2.0 \%$ & \\
\hline$\$ 2,151$ to $\$ 3,100$ & $6.1 \%$ & \\
\hline$\$ 3,101$ to $\$ 4,500$ & $0.0 \%$ & \\
\hline$\$ 4,501$ to $\$ 5,500$ & $0.0 \%$ & \\
\hline$\$ 5,501$ or more & $0.0 \%$ & \\
\hline \multicolumn{3}{|l|}{ Years in current location } \\
\hline Less than one year & $18.4 \%$ & \\
\hline $1-2$ years & $8.2 \%$ & \\
\hline 3-5 years & $18.4 \%$ & \\
\hline $6-9$ years & $12.2 \%$ & \\
\hline 10 years or longer & $42.9 \%$ & \\
\hline \multicolumn{3}{|l|}{ Time spent in current location yearly } \\
\hline About 3 month/not much of the year & $2.0 \%$ & \\
\hline About 6 months/about half of the year & $14 \cdot 3 \%$ & \\
\hline About 9 months/most of the year & $18.4 \%$ & \\
\hline 12 months/the entire year & $65 \cdot 3 \%$ & \\
\hline \multicolumn{3}{|l|}{ Social supports } \\
\hline \multicolumn{3}{|l|}{ Informal support ${ }^{\mathrm{a}}$} \\
\hline Elder family/clan member & $20.8 \%$ & \\
\hline Family/clan member about your own age & $28.3 \%$ & \\
\hline Friend & $18.2 \%$ & \\
\hline At least 1 informal support & $30.4 \%$ & \\
\hline \multicolumn{3}{|l|}{ Formal support ${ }^{\mathrm{a}}$} \\
\hline Doctor & $19.6 \%$ & \\
\hline Healer & $17.8 \%$ & \\
\hline Community worker & $11.4 \%$ & \\
\hline Mental health professional & $11.1 \%$ & \\
\hline Religious leader & $15.6 \%$ & \\
\hline Community leader & $15 \cdot 9 \%$ & \\
\hline At least 1 formal support & $24.4 \%$ & \\
\hline \multicolumn{3}{|l|}{ Mental health } \\
\hline \multicolumn{3}{|l|}{ Distress: Categorical } \\
\hline Low & $66.7 \%$ & \\
\hline Moderate & $22.9 \%$ & \\
\hline Severe & $10.4 \%$ & \\
\hline Distress: Continuous & 4.13 & 5.02 \\
\hline \multicolumn{3}{|l|}{ Happiness: Categorical } \\
\hline Not at all happy & $0.00 \%$ & \\
\hline A little happy & $0.00 \%$ & \\
\hline Somewhat happy & $2.1 \%$ & \\
\hline Happy & $54.2 \%$ & \\
\hline Very happy & $43.8 \%$ & \\
\hline Happiness: Continuous & 4.42 & 0.54 \\
\hline
\end{tabular}

Note. Ns ranged from 44 to 49 .

a. Percentages are percent of sample that responded Yes to each support system. 
with these findings, only $30.4 \%$ of individuals reported turning to at least one informal support the last time they felt sad, stressed, or worried. Moreover, only $24.4 \%$ of individuals reported turning to at least one formal support the last time they felt sad, stressed, or worried. These findings suggest that Somali men tended to use relatively few formal or informal supports that last time they felt sad, stressed, or worried.

With regard to mental health, findings indicated that $66.7 \%$ of participants exhibited low levels of distress (scores of 4 or less on the K6), 22.9\% exhibited moderate levels of distress (scores between 5 and 12 on the K6), and 10.4\% exhibited severe levels of distress (scores of 13 or above on the K6). In terms of happiness, most participants (98\%) reported being "happy" or "very happy" $(M=4.42, S D=0.54)$. The relations of perceived support to sociodemographic characteristics and mental health are reported in Table 2. Independent samples $t$ tests were conducted for continuous variables (age and distress) and MannWhitney $U$ tests were conducted for ordinal variables (income, years in current location, time spent in current location yearly, and happiness). As shown, there were trends (differences were marginally significant) in which individuals who reported turning to at least one formal support person tended to live longer in their current location and spend more time during the year in their current location than those who reported no formal supports. No differences were found for age or income variables between those who reported at least one formal support compared to those who did not report any formal supports. No differences were found on any sociodemographic variables between those who reported at least one informal support compared to those who did not report any informal supports.

Findings further revealed that individuals who reported at least one informal support had significantly higher levels of distress compared to those who did not report any informal supports. Similarly, individuals who reported at least one formal support had significantly higher levels of distress compared to those who did not report any formal supports. No differences were found between those who reported at least one informal support and those who did not report any informal supports on the measure of happiness. Similarly, no differences were found between those who reported at least one formal support and those who did not report any formal supports on the measure of happiness. 
Table 2. Relations of Perceived Informal and Formal Support to Sociodemographic Characteristics and Mental Health

\begin{tabular}{|c|c|c|c|c|c|c|}
\hline \multirow[b]{2}{*}{ Study variables } & \multicolumn{3}{|c|}{ Informal support } & \multicolumn{3}{|c|}{ Formal support } \\
\hline & Yes & No & $t / M-W U$ & Yes & No & $t / M-W U$ \\
\hline \multicolumn{7}{|c|}{ Sociodemographic characteristics } \\
\hline Age & $5.38(15.14)$ & $40.16(15.12)$ & -1.05 & $45.64(14.83)$ & $40.50(15.09)$ & -0.98 \\
\hline Income $^{a}$ & $24 \cdot 50$ & 23.06 & 210.00 & 23.91 & 22.71 & 177.00 \\
\hline Years in current location ${ }^{\mathrm{b}}$ & $27 \cdot 32$ & 21.83 & 170.50 & 28.86 & 21.10 & $122.50 \dagger$ \\
\hline $\begin{array}{l}\text { Time spent in current } \\
\text { location yearlyc }\end{array}$ & 26.36 & 22.25 & 184.00 & 28.77 & 21.13 & $123 \cdot 50^{\dagger}$ \\
\hline \multicolumn{7}{|l|}{ Mental health } \\
\hline Distress & $7.08(5.99)$ & $2.66(3.80)$ & $-2.47^{*}$ & $7.64(6.07)$ & $3.12(4.34)$ & $-2.70^{*}$ \\
\hline Happiness & $19 \cdot 77$ & $24 \cdot 31$ & 166.00 & 22.82 & 23.06 & 185.00 \\
\hline
\end{tabular}

Note. Ns ranged from 44 to 46 . The Yes category for both Informal support and Formal support includes individuals who reported at least one supportive person the last time they felt sad, stressed or worried. The No category for both Informal support and Formal support includes individuals who reported no supportive people the last time they felt sad, stressed or worried. Values under Yes and No columns represent Ms (SDs) for continuous variables (age and distress) and mean ranks for ordinal variables (income, years in current location, time spent in current location yearly, and happiness). Mean ranks were obtained by conducting MannWhitney $U(\mathrm{M}-\mathrm{W} U)$ tests. ts reported for continuous variables and M-W Us reported for ordinal variables.

a. Income was coded as follows: $1=\$ 0$ to $\$ 1,200,2=\$ 1,201$ to $\$ 1,750,3=\$ 1,751$ to $\$ 2,150,4=\$ 2,151$ to $\$ 3,100$, $5=\$ 3,101$ to $\$ 4,500,6=\$ 4,501$ to $\$ 5,500$, and $7=\$ 5,501$ or more.

b. Number of years residing in current location was coded as follows: $1=$ less than one year, $2=1-2$ years, $3=$ 3-5 years, $4=6-9$ years, and $5=10$ years or longer.

c. Average months spent in current location annually was coded as follows: $1=$ about 3 months/not much of the year, 2 = about 6 months/about half of the year, 3 = about 9 months/most of the year, and $4=12$ months/ the entire year.

$\dagger p<.10 ;{ }^{*} p<.05$.

\section{Discussion}

Our study examined perceived sources of emotional support and mental health of Somali refugees in a rural Midwest United States town. The presented town is not a designated refugee resettlement site and therefore does not have typical resettlement support mechanisms and agencies in place. As such, this study contributes to the presently scant literature on refugees in a postsecondary migration setting, specifically pertaining to Somalis' perceived formal and informal supports. Additionally, most research with Somali refugees in the United States focuses on women and youth; the analytic sample presented in this article consists entirely of adult men, providing new insight into this refugee group. 
We were surprised that participants generally reported low levels of distress and high levels of happiness. In a longitudinal study assessing Somali and Oromo refugees' premigration, transit, and postmigration stressors and mental health in the United States, Perera et al. (2013) found that Somali adults struggled to adapt to life in the United States. Difficulties participants reported included harsh Minnesota winter weather, language acquisition, unsanitary and unsafe housing conditions, unemployment and underemployment, and cultural differences (Perera et al., 2013). Adaptation difficulties have generally been associated with anxiety, depression, and PTSD among immigrant and refugee groups (Lincoln et al., 2016; Perera et al., 2013; Pumariega, Rothe, \& Pumariega, 2005). Additionally, Somalis have been shown to face discrimination in high-income resettlement countries, which has been associated with greater endorsement of depression and PTSD symptoms (Ellis et al., 2010; Mölsä, Kuittinen, Tiilikainen, Honkasalo, \& Punamäki, 2017). Inability to show feelings of happiness has been reported as a common occurrence among Somali refugees in postmigration settings, which is connected to psychological distress (Schuchman \& McDonald, 2008).

Previous research on African refugee integration in rural Minnesota provides a possible explanation for high self-reported mental health in our sample. Shandy and Fennelly (2006) found that even though Somali participants admitted challenges, they described stable wages, affordable housing, a peaceful community, and other quality of life indicators. Similarly, a study with ethnic Karen refugees from Burma (Myanmar) in Georgia revealed satisfaction with social networks, higher employment, affordable housing, and community among rural-residing Karen compared to urban counterparts (Gilhooly \& Lee, 2017). It is possible that quality of life factors explain high selfreported mental health among Somalis who migrated from an initial urban resettlement site; however, the study design makes this impossible to conclude. Similarly, high levels of happiness may be explained by religiosity and religious coping strategies, which have been established as improving psychosocial and mental health among African refugees, including Somalis (Adedoyin et al., 2016; Kroo \& Nagy, 2011; Silveira \& Allebeck, 2001). Another explanation may relate to Somali participants' sense of belonging and embeddedness in the community; more than $40 \%$ of participants reported living in the town for more than a decade, and 65\% stated they reside in the town for the 
entire year (i.e., not migrating seasonally). Additionally, the presence of a Somali community center may help newcomers overcome adjustment difficulties reported by Somalis in other studies (e.g., Ellis et al., 2010; Perera et al., 2013).

It is also important to consider Somalis' conceptualization of mental health. Guerin, Guerin, Diiriye, and Yates (2004) found that symptoms of depression (e.g., headaches, frequent crying, insomnia) were accepted as a normal part of life among many Somalis. Further, Nichter (1981) argued for the need to view ethnopsychiatric phenomena through what he termed "idioms of distress," ways of expressing distress that are imbued with cultural and contextual significance. Somali idioms of distress reveal distinct etiologies of emotional and psychological health problems (Im, Ferguson, \& Hunter, 2017; Mölsä, Hjelde, \& Tiilikainen, 2010; Ryan, 2008). For example, although idioms such as buufis (fixation on certain desires; Horst, 2006; Jinnah, 2017) and busqanaan (emotional distress characterized by physical and interpersonal/externalizing symptoms) share symptoms with anxiety disorders, context-specific explanations for these problems include lack of resources and opportunities as well as exposure to a variety of daily stressors (Im et al., 2017). Buufis-literally meaning "to blow" or "to inflate" in Somali-has been used by Somalis since arriving in Kenyan refugee camps in the 1990s to refer to an intense desire to be resettled abroad (Horst, 2006; Jinnah, 2017). Researchers later used buufis to describe a form of mental illness that occurred among Somalis who were not accepted for third-country resettlement (Jinnah, 2017). Contextualized in this manner, buufis provided a socioculturally acceptable way for Somalis to express distress related to limbo and extreme disappointment as shaped by external factors. It is possible, therefore, that internalizing indicators used in the psychological distress measure did not accurately assess mental health in this population.

Somali participants also reported low levels of both formal and informal supports. Previous literature on Somalis' social support in high-income countries highlights dissatisfaction with lack of family and ethnic group support in resettlement in tandem with nostalgia for the informal peer support that existed in Somalia (McMichael \& Manderson, 2004; Mölsä et al., 2010; Silveira \& Allebeck, 2001; Stewart et al., 2008). Stewart et al. (2008) also found that Somali newcomers in Canada first relied on other Somalis; however, after exhausting these 
networks, they were more likely to seek support from formal agencies and institutions. This is also notable, as Somali men have been shown to distrust formal public assistance institutions in resettlement contexts as reliance on welfare challenges Somali male authority (Abdi, 2014; Kleist, 2010). Results indicated that Somali men who had one supportive other compared to those who reported no supportive others had higher levels of distress. This was true for both informal and formal supports and appears to contradict hypotheses that social support may exert its effects through positive social relationships that enhance subjective well-being (e.g., Sarason, Sarason, \& Gurung, 1997). One possibility is that individuals experiencing more symptoms of anxiety and depression utilized supports more frequently, meaning that individuals feeling distress utilized their support systems. There is additional need for longitudinal research to see if seeking support leads to reductions in distress over time. Conversely, it could mean that individuals in perceived support networks were not meeting the needs of participants, leading to increased distress. Additional exploration of quality and functionality of social support is an important area for future research with Somali refugees as some participants may have rich and highly supportive friendship networks without any familial networks whereas others may have more diverse but lower quality support across multiple different sources (see WittenbergLyles, Washington, Demiris, Oliver, \& Shaunfield, 2014).

\section{Study Limitations and Strengths}

Study limitations should be noted. First, measures only examined sources of emotional support rather than quality, frequency, or types of supports within each source. Measures of mental health also consisted of a relatively brief screening measure that largely captures psychological distress, whereas more comprehensive measures of specific disorders may have yielded different results. Additional limitations resulted from the sampling strategy. Most notably, only three Somali women participated in this study. Researchers using RDS recruitment methods may wish to provide coupons to equal numbers of female and male participants to see if this increases representation in sampling. Conversely, convenience sampling may be needed to reach this subgroup. Finally, premigration, transit, and postmigration trauma and stressors were not assessed in this study, although each has been 
shown to be associated with postmigration mental health status (de Arellano et al., 2018; Gudiño, Nadeem, Kataoka, \& Lau, 2011; Perera et al., 2013; Perreira \& Ornelas, 2013).

The study should also be considered in light of its strengths and new contributions. One such strength is the inclusion of a hard-toreach rural refugee population in a postsecondary migration context. The assessment of sources of emotional support in these settings contributes to our understanding of how supports have been created or maintained in new destinations. Additionally, two aspects of mental health were investigated: distress and happiness. To our knowledge, this is the first study that examines self-rated happiness among refugee populations in the rural United States. Increasingly, happiness is being used conceptually to evaluate individuals' subjective well-being (Hendriks \& Bartram, 2018) and has potential to inform mental and psychosocial health research with refugee groups.

\section{Practical Implications and Conclusion}

The results of this study provide evidence of heterogeneity of perceived sources of support as well as of pluralistic help-seeking behaviors among Somali refugees in a new-destination rural United States context. Importantly, this adds nuanced, contextual understanding related to perceived social support in postsecondary migration settings. We have identified two practical implications from this study. First, task shifting interventions that utilize lay health workers to address mental health have shown promise with refugee populations globally (Javadi, Feldhaus, Mancuso, \& Ghaffar, 2017). Specific task shifting to enhance the quality of social support and expand access to supportive networks may improve the subjective well-being and mental health status of immigrant and refugee groups in rural settings in high-income countries. For example, Stewart et al. (2011) piloted a culturally tailored peer support intervention among Somali and Sudanese refugees in Canada. Participants and peer supporters were matched by sex and ethnicity; the intervention was comprised of biweekly support groups in tandem with individual support via telephone. Participants reported increased perceived support, decreased loneliness, and increased self-efficacy regarding navigating community resources (Stewart et al., 2011). Given appropriate community resources, a similar social support intervention may have success in 
rural contexts.

Second, health providers may wish to consider Somali refugees' distinct mental health etiologies in diagnoses and treatment. It could be valuable to integrate cultural sensitivity or cross-cultural communication instruction into health professional training and continuing medical education, as culturally tailored assessment, diagnosis, and treatment has shown some promise for reducing racial and ethnic health disparities in mental health care (Kohn-Wood \& Hooper, 2014). However, in a systematic review of cultural sensitivity training, Lie, LeeRey, Gomez, Bereknyei, and Braddock (2011) caution that existing evidence pertaining to educating health professionals is limited and not generalizable (e.g., curricula to replicate findings, not controlling for patient-provider variables.).

This study provides a starting point for mental health research that focuses on place and emplacement and that directly compares the nature of community resources, perceived support, and psychological distress among refugees residing in rural and urban settings.

Acknowledgments - Funding for this project was provided by the University of Nebraska-Lincoln Rural Futures Institute. Additional funding was provided by the University of Nebraska-Lincoln's College of Arts and Sciences (Enhance Grant 210524-0011). This project is based on research that was partially supported by the Nebraska Agricultural Experiment Station with funding from the Hatch capacity funding program (Accession 1011764) from the United States Department of Agriculture National Institute of Food and Agriculture.

\section{References}

Abdel-Khalek, A. M. (2006). Measuring happiness with a single-item scale. Social Behavior and Personality: An International Journal, 34, 139-150. doi:10.2224/ sbp.2006.34.2.139

Abdi, C. M. (2007). Convergence of civil war and the religious right: Reimagining Somali women. Signs, 33, 183-207. doi:10.1086/518393

Abdi, C. M. (2014). Threatened identities and gendered opportunities: Somali migration to America. Signs, 39, 459-483. doi:10.1086/673380

Abraham, R., Lien, L., \& Hanssen, I. (2018). Coping, resilience and posttraumatic growth among Eritrean female refugees living in Norwegian asylum reception centres: A qualitative study. International Journal of Social Psychiatry, 64, 359366. doi:10.1177/0020764018765237 
Adam, H. M. (1992). Somalia: Militarism, warlordism or democracy? Review of African Political Economy, 19, 11-26. doi:10.1080/03056249208703950

Adedoyin, A. C., Bobbie, C., Griffin, M., Adedoyin, O. O., Ahmad, M., Nobles, C., \& Neeland, K. (2016). Religious coping strategies among traumatized African refugees in the United States: A systematic review. Social Work \& Christianity, 43, 95-107.

Almeida, J., Molnar, B. E., Kawachi, I., \& Subramanian, S. V. (2009). Ethnicity and nativity status as determinants of perceived social support: Testing the concept of familism. Social Science \& Medicine, 68, 1852-1858. doi:10.1016/j. socscimed.2009.02.029

BBC. (2018, January4). Somalia country profile. Retrieved from https://www.bbc. com/news/world-africa-14094503

Beiser, M. (1999). Strangers at the gate: The" boat people's" first ten years in Canada. Toronto, Canada: University of Toronto Press. doi:10.3138/9781442680234

Bentley, J. A., Thoburn, J. W., Stewart, D. G., \& Boynton, L. D. (2012). Postmigration stress as a moderator between traumatic exposure and self-reported mental health symptoms in a sample of Somali refugees. Journal of Loss and Trauma, 17, 452-469. doi:10.1080/15325024.2012.665008

Bhui, K., Abdi, A., Abdi, M., Pereira, S., Dualeh, M., Robertson, D., ... Ismail, H. (2003). Traumatic events, migration characteristics and psychiatric symptoms among Somali refugees. Social Psychiatry and Psychiatric Epidemiology: The International Journal for Research in Social and Genetic Epidemiology and Mental Health Services, 38, 35-43. doi:10.1007/s00127-003-0596-5

Bose, P. S. (2018). Welcome and hope, fear, and loathing: The politics of refugee resettlement in Vermont. Peace and Conflict: Journal of Peace Psychology, 24, 320-329. doi:10.1037/pacoooo302

Broadway, M. (2007). Meatpacking and the transformation of rural communities: A comparison of Brooks, Alberta and Garden City, KS. Rural Sociology, 72, 560582. doi:10.1526/003601107782638701

Carroll, J. K. (2004). Murug, waali, and gini: Expressions of distress in refugees from Somalia. Primary Care Companion to the Journal of Clinical Psychiatry, 6, 119-125. doi:10.4088/PCC.vo6no3o3

Centers for Disease Control and Prevention. (2018). Refugee health profiles: Somali population movements. Retrieved from https://www.cdc.gov/ immigrantrefugeehealth/profiles/somali/populationMovements.html

Cohen, S., \& Wills, T. A. (1985). Stress, social support, and the buffering hypothesis. Psychological Bulletin, 98, 310-357. doi:10.1037/0033-2909.98.2.310

de Arellano, M. A., Andrews, A. R., III, Reid-Quiñones, K., Vasquez, D., Doherty, L. S., Danielson, C. K., \& Rheingold, A. (2018). Immigration trauma among Hispanic youth: Missed by trauma assessments and predictive of depression and PTSD symptoms. Journal of Latina/o Psychology, 6, 159-174. doi:10.1037/ latooooogo

Ellis, B. H., MacDonald, H. Z., Klunk-Gillis, J., Lincoln, A., Strunin, L., \& Cabral, H. J. (2010). Discrimination and mental health among Somali refugee adolescents: 
The role of acculturation and gender. American Journal of Orthopsychiatry, 80 , 564-575. doi:10.1111/j.1939-0025.2010.01061.x

Gerritsen, A. A., Bramsen, I., Devillé, W., van Willigen, L. H., Hovens, J. E., \& van der Ploeg, H. M. (2006). Physical and mental health of Afghan, Iranian and Somali asylum seekers and refugees living in the Netherlands. Social Psychiatry and Psychiatric Epidemiology: The International Journal for Research in Social and Genetic Epidemiology and Mental Health Services, 41, 18-26. doi:10.1007/s00127-005-0003-5

Gile, K. J., \& Handcock, M. S. (2010). Respondent-driven sampling: An assessment of current methodology. Sociological Methodology, 40, 285-327. doi:10.1111/j.1467-9531.2010.01223.x

Gilhooly, D., \& Lee, E. (2017). Rethinking urban refugee resettlement: A case study of one Karen community in rural Georgia, USA. International Migration, 55, 37-55. doi:10.1111/imig.12341

Goodkind, J. R. (2006). Promoting Hmong refugees' well-being through mutual learning: Valuing knowledge, culture, and experience. American Journal of Community Psychology, 37, 129-140. doi:10.1007/s10464-005-9003-6

Goodkind, J. R., Hess, J. M., Isakson, B., LaNoue, M., Githinji, A., Roche, N., ... Parker, D. P. (2014). Reducing refugee mental health disparities: A communitybased intervention to address postmigration stressors with African adults. Psychological Services, 11, 333-346. doi:10.1037/aoo35081

Gudiño, O. G., Nadeem, E., Kataoka, S. H., \& Lau, A. S. (2011). Relative impact of violence exposure and immigrant stressors on Latino youth psychopathology. Journal of Community Psychology, 39, 316-335. doi:10.1002/jcop.20435

Guerin, B., Guerin, P. B., Diiriye, R. O., \& Yates, S. (2004). Somali conceptions and expectations concerning mental health: Some guidelines for mental health professionals. New Zealand Journal of Psychology, 33, 59-67.

Halcón, L. L., Robertson, C. L., Savik, K., Johnson, D. R., Spring, M. A., Butcher, J. N., ... Jaranson, J. M. (2004). Trauma and coping in Somali and Oromo refugee youth. Journal of Adolescent Health, 35, 17-25. doi:10.1016/j. jadohealth.2003.08.005

Hammond, L. (2014). Somali refugee displacements in the near region: Analysis and recommendations. (Paper for the UNHCR Global Initiative on Somali Refugees). Geneva, Switzerland: United Nations Refugee Agency.

Heckathorn, D. D. (2002). Respondent-driven sampling II: Deriving valid population estimates from chain-referral samples of hidden populations. Social Problems, 49, 11-34. doi:10.1525/sp.2002.49.1.11

Hendriks, M., \& Bartram, D. (2018). Bringing happiness into the study of migration and its consequences: What, why, and how? Journal of Immigrant \& Refugee Studies, 17, 279-298.

Horst, C. (2006). Buufis amongst Somalis in Dadaab: The transnational and historical logics behind resettlement dreams. Journal of Refugee Studies, 19, 143-157. doi:10.1093/jrs/fejo17

Huisman, K. A. (2011). Why Maine? Secondary migration decisions of Somali refugees. Irinkerindo: A Journal of African Migration, 5, 55-94. 
Human Rights Watch. (2011, August14). "You don't know who to blame": War crimes in Somalia. Retrieved from https://www.hrw.org/report/2011/08/14/ you-dont-know-who-blame/war-crimes-somalia

Im, H., Ferguson, A., \& Hunter, M. (2017). Cultural translation of refugee trauma: Cultural idioms of distress among Somali refugees in displacement. Transcultural Psychiatry, 54, 626-652. doi:10.1177/1363461517744989

Internal Displacement Monitoring Centre (IDMC). (2006, January10). Somalia: window of opportunity for addressing one of the world's worst internal displacement crises. Retrieved from https://www.internal-displacement. org/sites/default/files/publications/documents/200601-af-somalia-somaliawindow-of-opportunity-for-addressing-one-of-the-worlds-worst-internaldisplacement-crises-country-en.pdf

Jaranson, J. M., Butcher, J., Halcon, L., Johnson, D. R., Robertson, C., Savik, K., ... Westermeyer, J. (2004). Somali and Oromo refugees: Correlates of torture and trauma history. American Journal of Public Health, 94, 591-598. doi:10.2105/ AJPH.94.4.591

Javadi, D., Feldhaus, I., Mancuso, A., \& Ghaffar, A. (2017). Applying systems thinking to task shifting for mental health using lay providers: A review of the evidence. Global Mental Health, 4, e14. doi:10.1017/gmh.2017.15

Jinnah, Z. (2017, March). Cultural causations and expressions of distress: A case study of buufis amongst Somalis in Johannesburg. Urban Forum, 28, 111-123.

Kapteijns, L., \& Arman, A. (2008). Educating immigrant youth in the United States: An exploration of the Somali case. Bildhaan: An International Journal of Somali Studies, 4, 6.

Kawachi, I., \& Berkman, L. F. (2001). Social ties and mental health. Journal of Urban Health, 78, 458-467. doi:10.1093/jurban/78.3.458

Kessler, R. C., Barker, P. R., Colpe, L. J., Epstein, J. F., Gfroerer, J. C., Hiripi, E., ... Zaslavsky, A. M. (2003). Screening for serious mental illness in the general population. Archives of General Psychiatry, 6o, 184-189. doi:10.1001/ archpsyc.6o.2.184

Keygnaert, I., Dialmy, A., Manço, A., Keygnaert, J., Vettenburg, N., Roelens, K., \& Temmerman, M. (2014). Sexual violence and sub-Saharan migrants in Morocco: A community-based participatory assessment using respondent driven sampling. Globalization and Health, 10, 32. doi:10.1186/1744-8603-10-32

Kleist, N. (2010). Negotiating respectable masculinity: Gender and recognition in the Somali diaspora. African Diaspora, 3, 185-206. doi:10.1163/187254610X526913

Kohn-Wood, L., \& Hooper, L. (2014). Cultural competency, culturally tailored care, and the primary care setting: Possible solutions to reduce racial/ethnic disparities in mental health care. Journal of Mental Health Counseling, 36, 173188. doi:10.17744/mehc.36.2.d73h217181tg6uv3

Kroo, A., \& Nagy, H. (2011). Posttraumatic growth among traumatized Somali refugees in Hungary. Journal of Loss and Trauma, 16, 440-458. doi:10.1080/15 325024.2011.575705

Lakey, B., \& Orehek, E. (2011). Relational regulation theory: A new approach to explain the link between perceived social support and mental health. Psychological Review, 118, 482-495. doi:10.1037/aoo23477 
Lie, D. A., Lee-Rey, E., Gomez, A., Bereknyei, S., \& Braddock, C. H., III.

(2011). Does cultural competency training of health professionals improve patient outcomes? A systematic review and proposed algorithm for future research. Journal of General Internal Medicine, 26, 317-325. doi:10.1007/ s116o6-010-1529-o

Lincoln, A. K., Lazarevic, V., White, M. T., \& Ellis, B. H. (2016). The impact of acculturation style and acculturative hassles on the mental health of Somali adolescent refugees. Journal of Immigrant and Minority Health, 18, 771-778. doi:10.1007/s10903-015-0232-y

Marks, J. (2014). Rural refugee resettlement: Secondary migration and community integration in Fort Morgan, Colorado. Retrieved from https://www.refworld. org/docid/543f8oaa4.html

Marmot, M. G., Syme, S. L., Kagan, A., Kato, H., Cohen, J. B., \& Belsky, J. (1975). Epidemiologic studies of coronary heart disease and stroke in Japanese men living in Japan, HI and California: Prevalence of coronary and hypertensive heart disease and associated risk factors. American Journal of Epidemiology, 102, 514-525. doi:10.1093/oxfordjournals.aje.a112189

Matheson, K., Jorden, S., \& Anisman, H. (2008). Relations between trauma experiences and psychological, physical and neuroendocrine functioning among Somali refugees: Mediating role of coping with acculturation stressors. Journal of Immigrant and Minority Health, 10, 291-304. doi:10.1007/ s10903-007-9086-2

McMichael, C., \& Ahmed, M. (2003, December). Family separation: Somali women in Melbourne. Paper presented at the Refugee Rights Symposium, Deakin University, Institute for Citizenship and Globalisation, Faculty of Arts, Melbourne, Australia.

McMichael, C., \& Manderson, L. (2004). Somali women and well-being: Social networks and social capital among immigrant women in Australia. Human Organization, 63, 88-99. doi:10.17730/humo.63.1.nwlpjdj4d4l97561

Moldovan, C. P. (2017). AM Happy Scale: Reliability and validity of a single-item measure of happiness (Doctoral dissertation). Loma Linda University, Loma Linda, CA.

Mölsä, M. E., Hjelde, K. H., \& Tiilikainen, M. (2010). Changing conceptions of mental distress among Somalis in Finland. Transcultural Psychiatry, 47, 27630o. doi:10.1177/1363461510368914

Mölsä, M., Kuittinen, S., Tiilikainen, M., Honkasalo, M. L., \& Punamäki, R. L. (2017). Mental health among older refugees: The role of trauma, discrimination, and religiousness. Aging \& Mental Health, 21, 829-837. doi:10.1 o80/13607863.2016.1165183

Montealegre, J. R., Risser, J. M., Selwyn, B. J., McCurdy, S. A., \& Sabin, K. (2013). Effectiveness of respondent driven sampling to recruit undocumented Central American immigrant women in Houston, TX for an HIV behavioral survey. AIDS and Behavior, 17, 719-727. doi:10.1007/s10461-012-0306-y

Mott, T. E. (2010). African refugee resettlement in the U. S.: The role and significance of voluntary agencies. Journal of Cultural Geography, 27, 1-31. doi:10.1080/o887363100359319o 
Muhwezi, W. W., \& Sam, D. L. (2004). Adaptation of urban refugees in Uganda: A study of their socio-cultural and psychological well being in Kampala city. Journal of Psychology in Africa; South of the Sahara, the Caribbean, and AfroLatin America, 14, 37-46. doi:10.4314/jpa.v14i1.306o8

Nichter, M. (1981). Idioms of distress: Alternatives in the expression of psychosocial distress: A case study from South India. Culture, Medicine and Psychiatry, 5, 379-408. doi:10.1007/BFoo054782

Pavlish, C. L., Noor, S., \& Brandt, J. (2010). Somali immigrant women and the American health care system: Discordant beliefs, divergent expectations, and silent worries. Social Science \& Medicine, 71, 353-361. doi:10.1016/j. socscimed.2010.04.010

Perera, S., Gavian, M., Frazier, P., Johnson, D., Spring, M., Westermeyer, J., . . .Jaranson, J. (2013). A longitudinal study of demographic factors associated with stressors and symptoms in African refugees. American Journal of Orthopsychiatry, 83, 472-482. doi:10.1111/ajop.12047

Perreira, K. M., \& Ornelas, I. (2013). Painful passages: Traumatic experiences and post-traumatic stress among immigrant Latino adolescents and their primary caregivers. The International Migration Review, 47, 976-1005. doi:10.1111/ imre.12050

Pratt, R., Ahmed, N., Noor, S., Sharif, H., Raymond, N., \& Williams, C. (2017). Addressing behavioral health disparities for Somali immigrants through group cognitive behavioral therapy led by community health workers. Journal of Immigrant and Minority Health, 19, 187-193. doi:10.1007/s10903-015-0338-2

Prochaska, J. J., Sung, H. Y., Max, W., Shi, Y., \& Ong, M. (2012). Validity study of the $\mathrm{K} 6$ scale as a measure of moderate mental distress based on mental health treatment need and utilization. International Journal of Methods in Psychiatric Research, 21, 88-97. doi:10.1002/mpr.1349

Pumariega, A. J., Rothe, E., \& Pumariega, J. B. (2005). Mental health of immigrants and refugees. Community Mental Health Journal, 41, 581-597. doi:10.1007/s10597-005-6363-1

Puyat, J. H. (2013). Is the influence of social support on mental health the same for immigrants and non-immigrants? Journal of Immigrant and Minority Health, 15, 598-605. doi:10.1007/s10903-012-9658-7

Refugee Processing Center. (n.d.). Interactive reporting: Admissions and arrivals. Retrieved from https://ireports.wrapsnet.org/InteractiveReporting/ EnumType/Report?ItemPath=/rpt WebArrivalsReports/Map\%20-\%20 Arrivals $\% 20$ by $\% 20$ State $\% 20$ and $\% 20$ Nationality

Rego, A., Machado, F., Leal, S., \& Cunha, M. P. E. (2009). Are hopeful employees more creative? An empirical study. Creativity Research Journal, 21, 223-231. doi:10.1080/10400410902858733

Rhodes, S. D., McCoy, T. P., Hergenrather, K. C., Vissman, A. T., Wolfson, M., Alonzo, J., ... Eng, E. (2012). Prevalence estimates of health risk behaviors of immigrant latino men who have sex with men. The Journal of Rural Health, 28, 73-83. doi:10.1111/j.1748-0361.2011.00373.x

Ryan, J. F. (2008). Going 'walli' and having 'jinni': Exploring Somali expressions of psychological distress and approaches to treatment (Doctoral dissertation). University of Waikato, Hamilton, New Zealand. 
Sarason, B., Sarason, I., \& Gurung, R. (1997). Close personal relationships and health outcomes: A key to the role of social support. In S. Duck (Ed.), Handbook of personal relationships: Theory, research and interventions (2nd ed., pp. 547573). Chichester, UK: Wiley.

Schuchman, B. D. M., \& McDonald, C. (2008). Somali mental health. Bildhaan: An International Journal of Somali Studies, 4, 8.

Schweitzer, R., Greenslade, J., \& Kagee, A. (2007). Coping and resilience in refugees from the Sudan: A narrative account. Australian and New Zealand Journal of Psychiatry, 41, 282-288. doi:10.1080/00048670601172780

Schweitzer, R., Melville, F., Steel, Z., \& Lacherez, P. (2006). Trauma, postmigration living difficulties, and social support as predictors of psychological adjustment in resettled Sudanese refugees. Australian and New Zealand Journal of Psychiatry, 40, 179-187. doi:10.1080/j.1440-1614.2006.01766.x

Shandy, D. J., \& Fennelly, K. (2006). A comparison of the integration experiences of two African immigrant populations in a rural community. Social Thought, $25,23-45$.

Shannon, P. J., Wieling, E., McCleary, J. S., \& Becher, E. (2015). Exploring the mental health effects of political trauma with newly arrived refugees. Qualitative Health Research, 25, 443-457. doi:10.1177/1049732314549475

Silveira, E., \& Allebeck, P. (2001). Migration, ageing and mental health: An ethnographic study on perceptions of life satisfaction, anxiety and depression in older Somali men in east London. International Journal of Social Welfare, 10, 309-320. doi:10.1111/1468-2397.00188

Simich, L., Beiser, M., \& Mawani, F. N. (2003). Social support and the significance of shared experience in refugee migration and resettlement. Western Journal of Nursing Research, 25, 872-891. doi:10.1177/0193945903256705

Stewart, M., Anderson, J., Beiser, M., Mwakarimba, E., Neufeld, A., Simich, L., \& Spitzer, D. (2008). Multicultural meanings of social support among immigrants and refugees. International Migration, 46, 123-159. doi:10.1111/j.1468-2435.2008.00464.X

Stewart, M., Simich, L., Beiser, M., Makumbe, K., Makwarimba, E., \& Shizha, E. (2011). Impacts of a social support intervention for Somali and Sudanese refugees in Canada. Ethnicity and Inequalities in Health and Social Care, 4, 186-199. doi:10.1108/17570981111250840

Streeter, C. L., \& Franklin, C. (1992). Defining and measuring social support: Guidelines for social work practitioners. Research on Social Work Practice, 2, 81-98. doi:10.1177/104973159200200107

Tippens, J. A. (2020). Generational Perceptions of Support Among Congolese Refugees in Urban Tanzania. Global Social Welfare, 7, 69-80.

Tonsing, K., Zimet, G. D., \& Tse, S. (2012). Assessing social support among South Asians: The Multidimensional Scale of Perceived Social Support. Asian Journal of Psychiatry, 5, 164-168. doi:10.1016/j.ajp.2012.02.012

United Nations Refugee Agency. (2019). Refugee resettlement facts. Retrieved from https://www.unhcr.org/en-us/resettlement.html United States Department of Agriculture. (2019, Apr9). What is rural? Retrieved from https://www.ers.usda.gov/topics/rural-economy-population/ rural-classifications/what-is-rural/ 
United States Department of Health and Human Services, Administration for Children and Families, Office of Refugee Resettlement. (2015, September14). The U.S. refugee resettlement program: An overview. Retrieved from https://www.acf.hhs.gov/orr/resource/ the-us-refugee-resettlement-program-an-overview

Walls, M. (2009). The emergence of a Somali state: Building peace from civil war in Somaliland. African Affairs, 108, 371-389.

Warfa, N., Curtis, S., Watters, C., Carswell, K., Ingleby, D., \& Bhui, K. (2012). Migration experiences, employment status and psychological distress among Somali immigrants: A mixed-method international study. BMC Public Health, 12,749 .

Wittenberg-Lyles, E., Washington, K., Demiris, G., Oliver, D. P., \& Shaunfield, S. (2014). Understanding social support burden among family caregivers. Health Communication, 29, 901-910. doi:10.1080/10410236.2013.815111 